Iranian Journal of Breast

DiseaseV 2021; 13(4):77-79.

Receive: 6/12/2020

Accepted: 12/12/2020

Corresponding Author:

msepandi@gmail.com

Ethics Approval:

Not applicable
Letter to the Editor

\section{A Critique of "Effect of 10 Weeks of High-Intensity Interval Training on Protein Levels of NF-kB and Expression of Atrogin-1 and MuRF-1 in Cardiomyocytes of Female Mice with Breast Cancer"}

\section{Sepandi M}

Health Research Center, Life Style Institute, Baqiyatallah University of Medical Sciences, Tehran, Iran
In Volume 13, Issue 3 of Iranian Quarterly Journal of Breast Diseases, an article entitled "Effect of 10 Weeks of High-Intensity Interval Training on Protein Levels of NF-kB and Expression of Atrogin-1 and MuRF-1 in Cardiomyocytes of Female Mice with Breast Cancer" has been published on pages 62-71. This article contains useful and practical information, but it seems necessary to pay attention to a few points:

In the statistical analysis section, the authors of the article state that: "First, the normality of the data was used by Kolmogorov-Smirnov test. An independent t-test was then used to examine the differences between the training and control groups. The Pearson Correlation Coefficient was used to determine the relationship between heart weight and protein levels of Atrogin-1 and MuRF-1, NF-kB. SPPS software version 24 was used at a significance level of $\mathrm{P} \leq 0.05$ for all statistical analyzes" .The first point is that the presumption of normality of data distribution is the basis of many statistical tests. Descriptive or inferential methods can be used to examine the normality of the distribution of a quantitative variable. Descriptive methods include examining the mean, mode and median as well as drawing statistical graphs. There are also several tests to check the normality of data in statistical texts, but the most important are Kolmogorov-Smirnov, Lilliefors corrected Kolmogorov-Smirnov test and Shapiro- Wilk test (1). The Kolomokrov- Smirnov test (written misspelt in the text of the article) is a test for quantitative data that compares the variable distribution in the sample with the distribution assumed for the population (2). One of the limitations of statistical tests is the statistical power and sensitivity of the test result to the sample size (3). The Shapiro-Wilk test has higher statistical power than the previous two cases, and some authors have introduced this test as the best option to check the normality of the data when the sample size is small (4).

Third, the independent t-test is a parametric test to compare the means of two samples (5). Therefore, it is better to show the average of the desired trait in the diagrams of 1 to 4 vertical axes. The fourth point is that under Figures 1 and 2, the phrase "significant decrease compared to the control group" is given, while the above diagrams show lower values in the control group, and this is a contradiction.

But the last point is that in Figures 1 to 4, the meaning of Error Bars is unknown. The use of error bars is usually very common in articles extracted from experimental studies, but it should be noted that the error bar in a chart may indicate standard deviation, standard error of the mean or confidence interval, and these three types of error bar are statistically different (6).

Therefore, it is so important to make clear what error bars represent via figure legends. Since one of the goals of the Iranian Quarterly Journal of Breast Diseases is to improve the quality of reports of articles published in the field of medicine, I hope that the above points will be considered, so that we can see an improvement in the quality of articles published our country. 
نامه باه سردبير

\section{نقدى بر مقاله \قاثير •| هفته اجراى تمرين تناوبى شديد بر بيان}

يروتئى NF-kB و بيان زنهاى Atrogin-1 و MuRF-1 در

مايوستهاى عضله قلبى موشهاى ماده مبتلا به سرطان بستان"

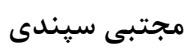

مركز تحقيقات بهداشت، بروهشكده سبك زندَّى، دانشكاه علوم يزشكى بقيه الهه (ع)، تهران، ايران
فصلنامه بيمارى هاى بستان ايران

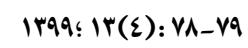

تاريخ ارسال: 99/9/9

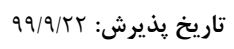

نويسنده مسئول: msepandi@gmail.com
Kolmogorov- آنها عبارتند ازي؛ آزمونهاى Lilliefors corrected Kolmogorov-،Smirnov Smirnov اسميرنوف (كه در متن مقاله با اشتباه تاييى نوشته شده آندان

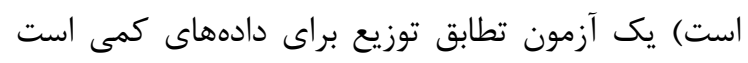

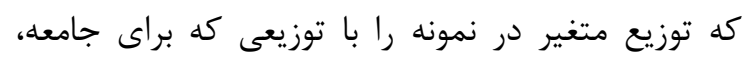

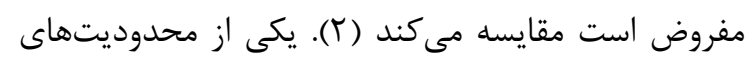

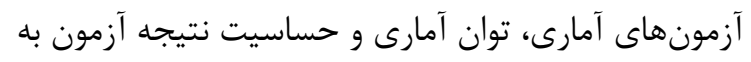

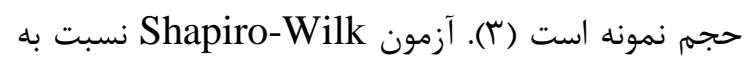

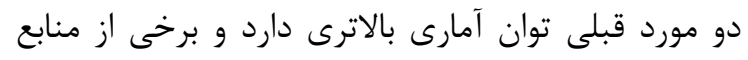

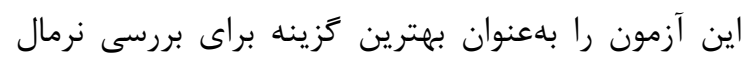

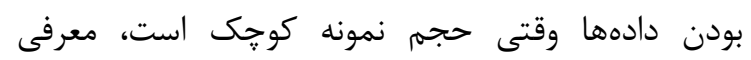

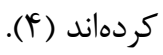
نكته دوم؛ عبارت سطح معنادارى

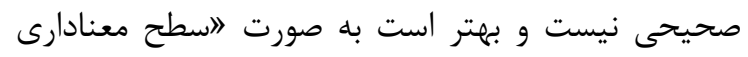

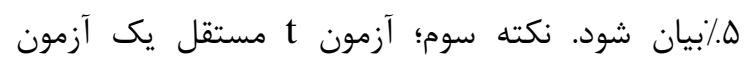

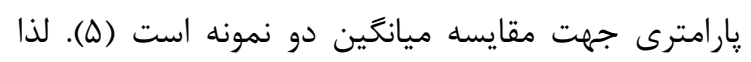

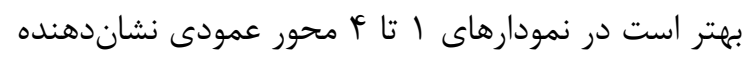
ميانكين صفت مورد نظر باشد.

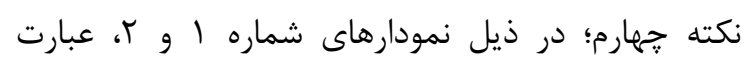

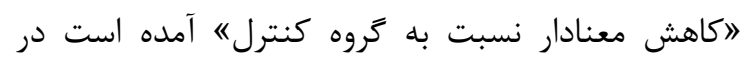
حالى كه نمودارهاى مذكور مقادير كمتر را در كروه كنترل نشان مى دهند و اين يك تناقض است.

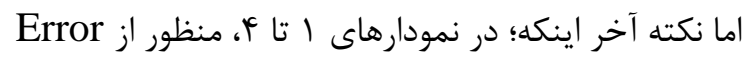

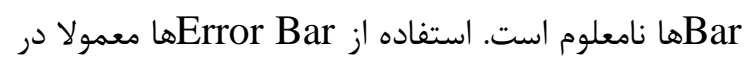

در جلد با شماره ب فصلنامه بيمارىهاى يستان ايران،

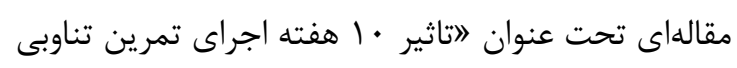

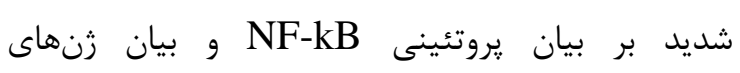
MuRF-1 Atrogin-1

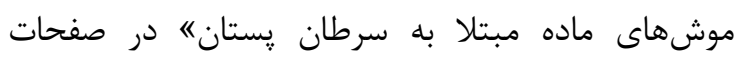

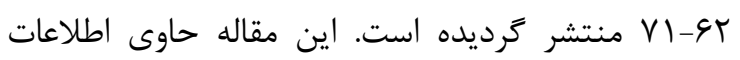

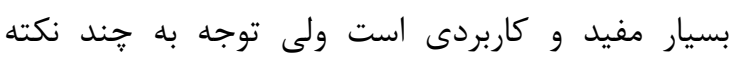
| ضرورى بلنظر مىرسد. نويسندًان محترم مقاله، در بخش تجرئ تجزيه و و تحليل آمارى

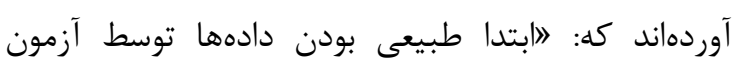

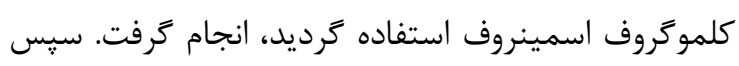

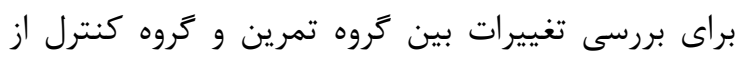

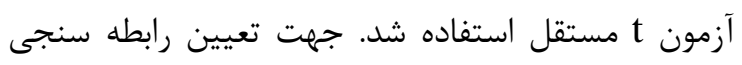

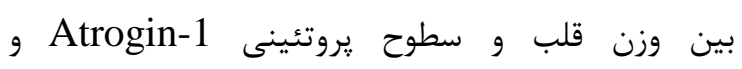
MuRF-1

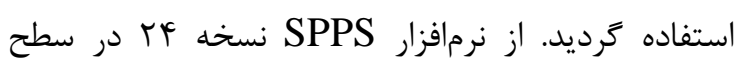
معنادارى P

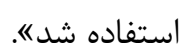

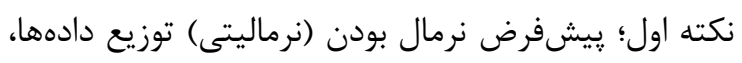

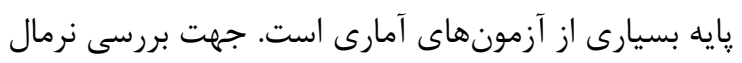

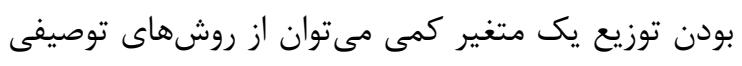

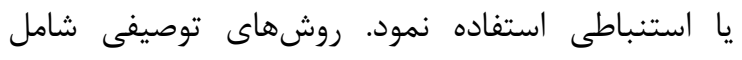
بررسى ميانخين، نما و ميانه و نيز رسم نمودارهاى آمارى نمادي

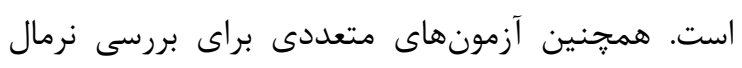

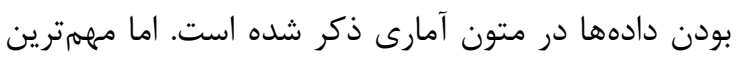


با توجه به اين كه يكى از اهداف فصلنامه بيمارىهاى

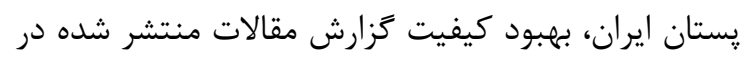

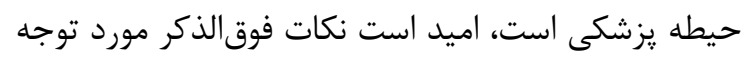

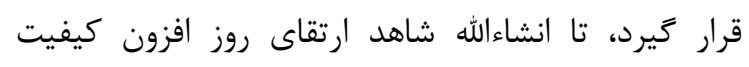
مقالات منتشر شده در داخل كشور باشيم.

\section{References}

1. Oztuna D, Elhan AH, Tuccar E. Investigation of four different normality tests in terms of type 1 error rate and power under different distributions. Turkish Journal of Medical Sciences. 2006; 36(3): 171-6.

2. Thode HC. Testing for normality: CRC press. 2002.

3. Steinskog DJ, Tjøstheim DB, Kvamstø NG. A cautionary note on the use of the KolmogorovSmirnov test for normality. Monthly Weather Review. 2007; 135(3):1151-7.
مقالات مستخرج از مطالعات تجربى شايع است. اما بايد توجه كرد Error Bar در يك نمودار مىتواند

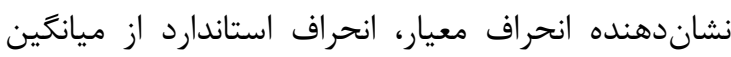

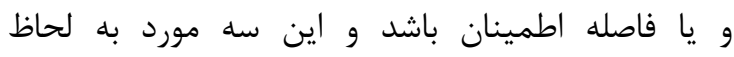
تفسير آمارى متفاوت هستند. لذا مشخص كردن نوع Bar Error

4. Razali NM, Wah YB. Power comparisons of shapiro- wilk, kolmogorov- smirnov, lilliefors and anderson-darling tests. Journal of statistical modeling and analytics. 2011;2(1): 21-33.

5. Rosner B. Fundamentals of biostatistics: Nelson Education. 2015.

6. Cumming G, Fidler F, Vaux DL. Error bars in experimental biology. The Journal of cell biology. 2007; 177(1):7-11. 